\title{
Association of the Resident Assessment Instrument (RAI) with Changes in Function, Cognition, and Psychosocial Status
}

\author{
Charles D. Phillips, $\mathrm{PhD}, \mathrm{MPH},{ }^{*}$ John N. Morris, $\mathrm{PhD},{ }^{+}$Catherine Hawes, $\mathrm{PhD},{ }^{\neq}$ \\ Brant E. Fries, $P h D,{ }^{\varsigma}$ Vincent Mor, $P h D, "$ Marianne Nennstiel, $B S^{\ddagger}$ and \\ Vincent Iannacchione, $M S^{\ddagger}$
}

\begin{abstract}
OBJECTIVE: To evaluate the impact of the Resident Assessment Instrument (RAI) on changes in nursing home residents' functional status, cognitive status, and psychosocial well-being. DESIGN: A quasi-experiment involving the collection of longitudinal data on two cohorts of nursing home residents. One cohort was assessed before the implementation of the $\mathrm{RAI}$, and the other was assessed after the implementation of the new assessment process.
\end{abstract}

SETTING AND PARTICIPANTS: Over 2000 nursing home residents in 267 nursing homes located in 10 geographic areas were assessed during the pre-RAI period. In the post-RAI period, 2000 new residents in 254 of the same facilities were assessed.

INTERVENTION: RAI implementation began in October 1990 and continued until October 1991. The RAI includes a structured, multidimensional resident assessment and problem identification system designed to form the basis for residents' care plans.

MEASUREMENTS: All residents were assessed at baseline and at 6 months using the Minimum Data Set for Nursing Home Resident Assessment and Care Screening (MDS) and its protocols. All data were collected by research nurses employed and trained by the research team.

RESULTS: Implementation of the RAI significantly reduced the rate of decline in seven of the nine outcomes under consideration. Reductions in improvement were also observed in all outcomes. In activities of daily living, social engagement, and cognitive function, the reduced decline far outweighed any reductions in improvement. In mood problems, problem behaviors, and understanding others, how-

\footnotetext{
From the "Myers Research Institute, Menorah Park Center for the Aging, Beachwood, Ohio; tResearch and Training Institute, Hebrew Rehabilitation Center for the Aged, Boston, Massachusetts; \$Program on Aging and Long-Term Care, Research Triangle Institute, Research Triangle Park, North Carolina; SInstitute of Gerontology and School of Public Health, University of Michigan, and the Veteran's Administration Medical Center, Ann Arbor, Michigan; and llCenter for Gerontology and Health Care Research, Brown University, Providence, Rhode Island. This research was supported by the Health Standards and Quality Bureau (HSQB) of the Health Care Financing Administration under Contract 500-880055 . The views expressed herein are, however, those of the authors and are not necessarily shared by the Health Care Financing Administration or the authors' sponsoring organizations.

Address correspondence to Charles D. Phillips, PhD, MPH Myers Research Institute, Menorah Park Center for the Aging, 27100 Cedar Rd., Beachwood, $\mathrm{OH}$ 44122-1156.
}

ever, reductions in improvement were greater than any reductions in decline. Changes in the rates of decline and improvement were not uniform across all residents.

CONCLUSION: The RAI may have improved the quality of care of nursing home residents by reducing overall rates of decline in important areas of resident function. However, this innovation may have generated trade-offs in that it may have reduced improvement rates in some areas of function. The system's implementation also seems to have focused staff's attention on the needs and strengths of specific subpopulations of residents. Revisions of the RAI must assist staff in generalizing their efforts to all residents and to increasing improvement rates, especially in areas related to mood and behavior. J Am Geriatr Soc 45:986-993, 1997.

$T$ here is little dispute in the clinical literature concerning the importance of assessment in caring for individual geriatric patients. As Applegate et al. ${ }^{1}$ indicated, "Comprehensive functional assessment of elderly patients in clinical settings is becoming essential for optimal clinical management." However, the available research on the effects of comprehensive geriatric assessment on population outcomes is somewhat contradictory. Reuben and his colleagues ${ }^{2}$ noted that "the usefulness of comprehensive geriatric assessment as a method of improving the health care of frail elderly persons is still in question."

A number of studies of geriatric assessment have demonstrated positive effects on geriatric patient outcomes, such as functional status, mortality, hospital use, and nursing home use. ${ }^{3-11}$ Other studies, looking largely at the effects of geriatric consultation teams, have shown little positive effect. ${ }^{2,12-14}$

\begin{tabular}{l} 
For editorial comment, \\
see pp 975, 1025, and 1027 \\
\hline Our research expands the discussion of the effects of \\
comprehensive geriatric assessment by evaluating its effects in \\
an environment quite different from that in which this process \\
has traditionally been evaluated. First, the assessment process \\
under investigation was implemented in a long-term care \\
setting-nursing homes. Second, it was mandated and sup- \\
ported by federal regulations. ${ }^{15-17}$ Third, the assessment \\
system was implemented in a clinical environment largely \\
controlled by nurses with limited physician involvement.
\end{tabular}


This report presents the results of one aspect of the more general evaluation - the assessment of the Resident Assessment Instrument (RAI)'s impact on resident outcomes. Specifically, in nine functional areas, we investigated hypotheses concerning whether residents in the post-RAI period experienced functional decline less frequently and functional improvement more frequently than did residents in the pre-RAI period.

\section{METHODS}

\section{Research Strategy}

Because the RAI was implemented nationally beginning in the fall of 1990, a pre/post quasi-experimental design was used for the evaluation. In the pre-RAI cohort, baseline assessments occurred in September and October 1990; follow-up assessments occurred 6 months later. The post-RAI resident cohort came from the same facilities as the pre-RAI cohort and were assessed in the spring and fall of 1993. By that time study facilities had used the RAI for approximately 2 years.

The 10 study states were selected to ensure that the RAI's impact would be evaluated in diverse environments with different Medicaid rates and staffing. Data collection in each state was concentrated in the counties in one metropolitan statistical area (MSA) and in the more rural counties adjacent to the chosen MSA. The study areas were Oakland, CA; Hartford, CT; Des Moines, IA; Baltimore, MD; Minneapolis, MN; Cleveland, OH; Portland, OR; Nashville, TN; Dallas, TX; and Virginia Beach/Newport News, VA. Some 24 to 28 facilities were chosen in each area. In both cohorts, an average of eight residents were randomly sampled in each facility. The sample was representative of the more than 50,000 nursing home residents in our 10 study areas.

All data collection was completed by registered nurses employed and trained by project staff. The research nurses reviewed a resident's medical record, the most recent 3 months of nursing notes related to the resident, and the resident's care plan. They then completed a full MDS assessment, which involved interviewing multiple caregivers (e.g., aides and licensed staff from different shifts) for each resident, observing the resident's care, and interviewing the resident. ${ }^{17,18}$

The 267 facilities participating in the pre-RAI data collection comprised $85 \%$ of the eligible facilities contacted and chosen for participation by project staff. Ninety-five percent (254) of these 267 facilities also participated in the post-RAI data collection. The pre-RAI cohort included 2170 residents in 267 facilities; the post-RAI cohort included 2088 residents in 254 facilities. Residents in facilities that dropped out of the study did not differ from residents in facilities that remained. In addition, at the resident level, there was no differential attrition across the cohorts. In both cohorts, just over $80 \%$ of the residents assessed at baseline were assessed at the 6-month follow-up. ${ }^{18}$

We investigated two initial hypotheses about rates of change for each of our outcomes. These hypotheses grew out of the expected effects of bringing systematic, multidimensional assessment into nursing homes. The following specific hypotheses were tested:

1. Residents in the post-RAI cohort were significantly less likely to experience decline than were members of the pre-RAI cohort.
2. Residents in the post-RAI cohort were significantly more likely to experience improvement than were members of the pre-RAI cohort.

\section{Measurement}

All the measures included in these analyses were based on MDS items. Activities of daily living (ADL) function, cognitive performance, urinary incontinence, bowel incontinence, making oneself understood, understanding others, social engagement, mood, and problem behaviors were the nine outcomes of interest. These outcomes were chosen for analysis because they are important functional areas, well captured by the MDS, that have major effects on residents' quality of life. ${ }^{19}$

To summarize the highly intercorrelated ADL measures a six-category ADL index was constructed from selfperformance scores on six ADLs: transfer, locomotion, dressing, eating, toileting, and bathing, as well as the score on urinary continence. ${ }^{20}$ The final reliabilities for the ADL Selfperformance measures used in this analysis ranged from .89 to .98 , whereas the reliabilities for bowel and bladder continence were .92 and .90 , respectively. ${ }^{21}$

The primary analysis of cognitive function used a summary measure that combines MDS items into a functional hierarchy of cognitive performance. The MDS Cognitive Performance Scale (CPS) has seven categories that move progressively from relatively independent cognitive performance to extreme cognitive impairment. ${ }^{22-25}$

Communication is also a major focus of inquiry in the MDS. For this analysis, we chose the two most general items for communication, "making oneself understood" and "ability to understand others." Both items had interrater reliability values above $90 .^{21}$

The MDS includes three sets of items to detect psychosocial impairment: social engagement, mood distress, and behavioral symptoms. The MDS social engagement scale is a six-item scale described elsewhere. ${ }^{26}$ The MDS sad or anxious mood scale is based on $12 \mathrm{MDS}$ items and exhibits moderate to good sensitivity and specificity when compared with clinical judgments made by trained facility staff. ${ }^{27}$ Using these items, residents were categorized as having no problem, a mild, a moderate, or a severe problem. The MDS unsettled behavior scale is based on the four MDS behavior items (i.e., wandering, physically abusive behavior, verbally abusive behavior, socially inappropriate behavior) and the MDS items on decision-making and persistence of a mood problem. The scale placed residents in one of four categories: no problem, mild, moderate, or severe problem. Early research indicates that this scale correlates well with staff judgments concerning the severity of a resident's behavioral problems. ${ }^{28}$

For each of the nine dependent variables, a resident's status at baseline was compared with her or his status at the 6-month follow-up. Based on these comparisons, each resident was placed in one of four outcome categories: exit, declined, improved, or stable. Those residents who left the facility before the follow-up had "exited." Residents whose score on a dependent variable at follow-up was better than their score at baseline had "improved." If a resident's follow-up score was worse than their baseline score, then that resident was placed in the "decline" category.

Covariates were included in the model to ensure that the results were adjusted for changes across the two cohorts that might affect outcomes. These independent variables included 
Table 1. Pre-RAI and Post-RAI Baseline Values in Two Cohorts

\begin{tabular}{|c|c|c|c|}
\hline Outcome & $\begin{array}{l}\text { Pre-RAI } \\
\text { Baseline B }\end{array}$ & $\begin{array}{l}\text { Post- } \\
\text { RAl } \\
\text { Baseline }\end{array}$ & $\begin{array}{c}\text { Significance o } \\
\text { Baseline } \\
\text { Differences* }\end{array}$ \\
\hline \multicolumn{4}{|l|}{ Physical Function } \\
\hline $\begin{array}{l}\text { ADL } \\
\text { Index }\end{array}$ & 3.11 & 3.18 & $\begin{array}{l}1.36 \\
(.17)\end{array}$ \\
\hline $\begin{array}{l}\text { Urinary } \\
\text { Incontinence }\end{array}$ & 1.85 & 2.06 & $\begin{array}{l}3.12 \\
(.002)\end{array}$ \\
\hline Bowel Incontinence & 1.87 & 1.89 & $\begin{array}{l}0.42 \\
(.67)\end{array}$ \\
\hline \multicolumn{4}{|c|}{$\begin{array}{l}\text { Cognition, Communication, } \\
\text { and Psychosocial } \\
\text { Well-Being }\end{array}$} \\
\hline $\begin{array}{l}\text { Cognitive } \\
\text { Performance }\end{array}$ & 3.03 & 3.06 & $\begin{array}{l}0.36 \\
(.72)\end{array}$ \\
\hline Being Understood & 0.98 & 1.00 & $\begin{array}{l}0.50 \\
(.62)\end{array}$ \\
\hline $\begin{array}{l}\text { Understanding } \\
\text { Others }\end{array}$ & 1.05 & 1.08 & $\begin{array}{l}0.70 \\
(.49)\end{array}$ \\
\hline $\begin{array}{l}\text { Social Engagement } \\
\text { Scale }\end{array}$ & 3.96 & 4.10 & $\begin{array}{l}1.62 \\
(.10)\end{array}$ \\
\hline $\begin{array}{l}\text { Sad or Anxious } \\
\text { Mood Scale }\end{array}$ & 1.30 & 1.29 & $\begin{array}{r}-1.50 \\
(.13)\end{array}$ \\
\hline $\begin{array}{l}\text { Unsettled Behavior } \\
\text { Scale }\end{array}$ & 1.29 & 1.25 & $\begin{array}{l}1.38 \\
(.17)\end{array}$ \\
\hline
\end{tabular}

* Entries are $t$ values with their probabilities in parentheses. Higher values indicate poorer function.

baseline values for the dependent variables. In addition, three scales were included in the models. Two of these scales, the CPS and the ADL index, were discussed above. The third scale was an MDS-based version of the Resource Utilization Groups-Version III (RUG-III) model. ${ }^{29}$ A resident's score on this scale reflects the relative amount of direct care they receive.

\section{Analytic Strategy}

The multivariate results derive from two logistic regression models estimated for each of the nine outcomes. One model estimated the likelihood that a resident would remain stable versus decline. One model estimated the likelihood that a resident would remain stable versus improve. When a resident had no likelihood of achieving the outcome under consideration, that resident was not included in the analysis. For example, a resident who could decline no further in urinary continence was excluded from the analysis of decline in urinary continence. Additional models were estimated to test whether other individual- or facility-level variables affected any observed differences between the cohorts. Alternative specifications for the dependent variables were also tested. Results for the individual ADLs were compared with those for the summary scale. A variety of multinomial logistic regression models were also estimated. All these analyses provided results completely consistent with the results presented below. To adjust for the effects of clustering, all results were produced using SUDAAN software, ${ }^{30}$ which provides appropriate variance estimates for clustered data. In addition, in some of our 10 geographic areas, our facility sample included a large proportion of the available facilities, and
SUDAAN allowed us to use the finite population correction in our variance estimates.

The main focus of the multivariate analysis was on the presence or absence of significant parameters in the logistic regressions. Although such parameters are important, they do not provide a clear picture of what happened to the resident population as a whole. For example, assume that in the post-RAI cohort, the relative, adjusted odds of improving in ADLs were only half the odds of improvement experienced by those in the pre-RAI cohort. Also, the relative, adjusted odds of decline in the post-RAI cohort were only half the odds of decline in the pre-RAI cohort. Fewer people declined and fewer improved in the post-RAI period.

What we do not know, however, is how the changes in improvement and decline "balanced out." In other words, did the intervention keep more people from declining than it kept from improving? Using our multinomial logistic regression models, we generated estimates of the differences in the number of residents who declined and improved in the preRAI and post-RAI cohorts. With these estimates of the number of residents declining and improving, we constructed ratios that compared the change in decline to the change in improvement (i.e., the difference in pre-RAI and post-RAI decline divided by the difference in pre-RAI and post-RAI improvement). These ratios, basically weighted rate ratios, are reported for each outcome. A ratio above 1.0 means that the reduction in the number of residents declining was greater than the reduction in the number of residents improving.

\section{RESULTS}

To place the results of the evaluation in context, it is important to provide some sense of how the study facilities and residents compared with the nursing home industry and nursing home resident population as a whole. Two such comparisons were carried out.

First, we compared the facilities in the MDS evaluation sample with all other Medicare- or Medicaid-certified facilities in the country using data from the Health Care Financing Administrations (HCFA)'s Online Survey and Certification Automated Record (OSCAR) system. The study sample mirrored the remaining facilities extraordinarily well in ownership, percentage Medicaid, and percentage Medicare. However, the study sample contained more large facilities due to the chosen sampling strategy, and the study facilities were somewhat better staffed than other facilities.

Second, we compared the 1990 baseline resident sample with the nationally representative sample from the 1987 National Medical Expenditures Survey-Institutional Population Component (NMES-IPC). ${ }^{31}$ The study sample contained significantly more females than did the NMES-IPC (78 vs $73 \%, P<.001)$. It also contained significantly fewer individuals with moderate ADL impairment ( 13 vs $19 \%, P<.001$ ), with slightly more individuals at either end of the ADL impairment scale. There were no significant differences in dementia levels, wandering, presence of physically abusive behavior, or in the age distribution of the over- 65 population.

Table 1 presents residents' pre-RAI and post-RAI baseline scores on the nine outcome measures. In seven functional areas, residents' baseline scores in the post-RAI period were slightly higher than in the pre-RAI period. In two areas, mood and behavior, one saw no change or a minor reduction. However, only in urinary incontinence was the difference large enough to be statistically significant. 
Table 2. Decline, Stability, and Improvement in the Pre-RAI and Post-RAI Cohorts

\begin{tabular}{|c|c|c|c|}
\hline Outcome & $\begin{array}{l}\text { Pre- } \\
\text { RAl } \\
\text { Cohort }\end{array}$ & $\begin{array}{l}\text { Post- } \\
\text { RAl } \\
\text { Cohort }\end{array}$ & $\begin{array}{c}\text { Statistical } \\
\text { Significance* }\end{array}$ \\
\hline \multicolumn{4}{|l|}{$\begin{array}{l}\text { Physical Function } \\
\text { ADL Index }\end{array}$} \\
\hline Decline & 25.9 & 18.8 & $<.001$ \\
\hline Stable & 43.3 & 55.0 & $<.001$ \\
\hline Improve & 12.9 & 9.5 & .001 \\
\hline \multicolumn{4}{|c|}{ Urinary Incontinence } \\
\hline Decline & 19.2 & 17.1 & .114 \\
\hline Stable & 52.0 & 57.0 & .003 \\
\hline Improve & 11.0 & 9.1 & .080 \\
\hline \multicolumn{4}{|c|}{ Bowel Incontinence } \\
\hline Decline & 17.7 & 14.9 & .040 \\
\hline Stable & 54.5 & 61.1 & $<.001$ \\
\hline Improve & 9.9 & 7.2 & $<.001$ \\
\hline \multicolumn{4}{|c|}{$\begin{array}{l}\text { Cognition, Communication, } \\
\text { and Psychosocial } \\
\text { Well-Being }\end{array}$} \\
\hline \multicolumn{4}{|c|}{ Cognitive Performance } \\
\hline Decline & 15.3 & 9.5 & $<.001$ \\
\hline Stable & 34.5 & 51.5 & $<.001$ \\
\hline Improve & 17.3 & 12.1 & $<.001$ \\
\hline \multicolumn{4}{|l|}{ Being Understood } \\
\hline Decline & 19.9 & 14.6 & $<.001$ \\
\hline Stable & 46.9 & 58.9 & $<.001$ \\
\hline Improve & 15.0 & 9.6 & $<.001$ \\
\hline \multicolumn{4}{|c|}{ Understanding Others } \\
\hline Decline & 21.6 & 16.4 & $<.001$ \\
\hline Stable & 44.0 & 56.0 & $<.001$ \\
\hline Improve & 18.4 & 10.8 & $<.001$ \\
\hline \multicolumn{4}{|c|}{ Social Engagement } \\
\hline Decline & 30.2 & 24.3 & $<.001$ \\
\hline Stable & 27.2 & 37.3 & $<.001$ \\
\hline Improve & 24.5 & 21.5 & .039 \\
\hline \multicolumn{4}{|c|}{ Sad or Anxious Mood } \\
\hline Decline & 9.9 & 9.6 & .808 \\
\hline Stable & 59.7 & 65.1 & .002 \\
\hline Improve & 12.0 & 8.2 & .002 \\
\hline \multicolumn{4}{|c|}{ Unsettled Behavior } \\
\hline Decline & 10.5 & 11.2 & .547 \\
\hline Stable & 58.0 & 63.0 & .004 \\
\hline Improve & 13.2 & 8.7 & $<.001$ \\
\hline
\end{tabular}

* Probability that the sample proportions for each outcome in the pre-RAI cohort are equal to those for the post-RAI cohort.

The two cohorts were also quite similar demographically. There were no significant differences in the gender distributions or age structures of the cohorts. However, there was a significant increase $(P<.001)$ in the proportion of residents receiving Medicaid. In the post-RAI cohort, $65 \%$ of the residents were on Medicaid, and in the pre-RAI cohort $59 \%$ were on Medicaid.

Table 2 indicates, for each outcome, the percentage of each cohort who declined, remained stable, or improved from baseline to follow-up. In both the pre-RAI and the post-RAI periods, the modal outcome was stability (i.e., no change) between baseline and the 6-month follow-up. This pattern was consistent across all nine outcomes. This increased stability in the post-RAI cohort was usually accompanied by both lower levels of decline and lower levels of improvement

As indicated earlier we estimated two multivariate models for each outcome. These models compared the likelihood, across the two cohorts, that a resident would experience decline or improvement versus the likelihood he or she would remain stable. The results are presented separately for those outcomes that represent physical function and for those outcomes closely tied to cognitive or psychosocial function. These dimensions of function are not independent, but they do reflect different goals of care that may demand different types of therapeutic efforts. ${ }^{32}$ One might reasonably expect the RAl's impact to differ across these dimensions.

Table 3 presents the results of the analysis of differences in rates of physical decline by displaying the relative oddsratios for the variables representing the differences between the pre-RAI and the post-RAI cohorts. In all three functional areas, residents in the post-RAI cohort were significantly less likely to decline. In addition, residents were significantly less likely to improve in the post-RAI cohort.

As the last row in Table 3 indicates, for the ADL index and urinary continence, the reductions in decline in the postRAI cohort heavily outweighed the reductions in improvement; on balance, population outcomes in these areas were much better in the post-RAI period. For changes in bowel continence rates, the differences in decline and improvement basically balanced each other; overall population outcomes in bowel continence did not really differ across the two cohorts.

To understand more clearly exactly which residents experienced a reduction in decline or improvement, residents were categorized into four groups. The two major covariates (i.e., the ADL index and the CPS) used in the logistic regression were transformed into dichotomies. These two dichotomies created four categories of residents. The difference in the decline rates and improvement rates for each group was directly compared across the two cohorts.

The results of these comparisons appear in Table 4. The cell entries indicate for each group whether significantly fewer residents declined in the post-RAI period, whether significantly fewer residents improved in the post-RAI period, or whether the outcomes for residents in a group displayed a "mixed" pattern of both significantly less improvement and less decline. Because a number of differences were evaluated, only those differences significant at .01 are displayed. Because these analyses are bivariate, they may not exactly mirror the results presented in Tables 3 .

As Table 4 indicates, in the physical functioning areas, the RAI's implementation seems to have focused staff on reducing decline among the more functionally impaired, at the possible expense of less improvement among the less impaired. Two of the three instances of significantly less improvement occurred among those with better ADL and cognitive function, whereas all three instances of significantly less decline occurred among those residents with the poorest ADL function.

Table 5 presents the logistic regression results for the models examining the likelihood of changes in cognition, communication, and psychosocial problems. As the table indicates, residents in the post-RAI cohort were significantly more likely to remain stable in their cognitive performance, 
Table 3. Adjusted Odds-Ratios for Parameters Reflecting Differences Between the Pre-RAI and Post-RAI Cohorts in Changes in Physical Function

\begin{tabular}{|c|c|c|c|}
\hline Outcome & \multicolumn{2}{|c|}{ Effects of the RAl on the Likelihood of: } & $\begin{array}{l}\text { Difference in Decline Divided by } \\
\text { Difference in Improvement }\end{array}$ \\
\hline Urinary Incontinence & $\begin{array}{c}.682 \\
(.533-.872)\end{array}$ & $\begin{array}{c}.540 \\
(.430-.724)\end{array}$ & 1.57 \\
\hline
\end{tabular}

Values appearing in parentheses below the adjusted relative odds-ratios are the $95 \%$ confidence intervals. Only those parameters for which $P<.01$ are displayed. Tables containing the full equations are available from the first author.

Table 4. Impact of RAI Implementation on Physical Functioning in Specific Resident Subpopulations

\begin{tabular}{lcccc}
\hline \multicolumn{1}{c}{ Outcomes } & Good ADL, Good CPS & Good ADL, Poor CPS & Poor ADL, Good CPS & Poor ADL, Poor CPS \\
\hline $\begin{array}{l}\text { ADL index } \\
\begin{array}{l}\text { Urinary incontinence } \\
\text { Bowel incontinence }\end{array}\end{array}$ & Fewer improve & Fewer decline & Fewer decline \\
\hline
\end{tabular}

Entries reflect mean differences in the rates of change that are statistically significant at the .01 level.

Table 5. Multivariate Results of the Effects of the RAI's Implementation on Changes in Cognition, Communication, and Psychosocial Status

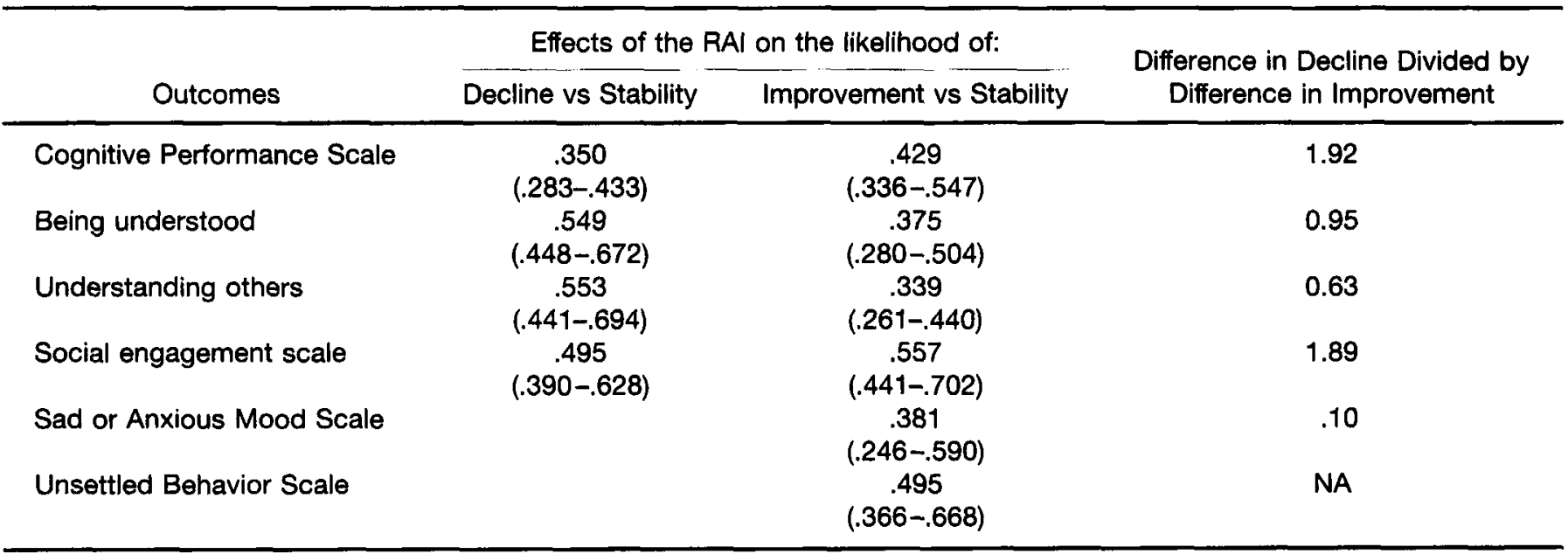

Values appearing in parentheses below the adjusted relative odds-ratios are the $95 \%$ confidence intervals. Only those parameters for which $P<.01$ are displayed. NA $=$ Ratio could not be computed because the post-RAl cohort evidenced increased decline and decreased improvement. Tables containing the full cquations are available from the first author.

communication skills, and social engagement than were residents in the pre-RAI cohort. With this increased stability, one sees both less improvement and less decline. Only in mood and behavior was there no reduction in decline, only a reduction in improvement.

Again, we analyzed whether these outcomes were in general better in the post-RAI period by looking at the ratio of reductions in decline to reductions in improvement. For our measure of cognitive performance, the change in decline far outweighed the change in improvement. For every individual who failed to improve in the post-RAI period, almost two individuals failed to decline. Roughly the same result occurred in social engagement. Reduced decline far outweighed reduced improvement. With being understood, the changes in decline and improvement rates were fundamentally equivalent; about as many people failed to decline as failed to improve. However, for understanding others, mood, and behavior, reductions in the post-RAI rates of improve- 
OBRA-87 reform package. It included the RAI, aide training requirements, restraint reduction requirements, psychotropic reduction requirements, staffing requirements, and changes in the survey process.

None of these specific reforms seems to present a reasonable explanation for the observed changes. Research indicates that the requirement related to the use of physical restraints and antipsychotic medications did have a positive effect on quality. ${ }^{33,35}$ However, when we added these factors into our multivariate models, the cohort (i.e., intervention) effect was unchanged. Aide training was implemented under OBRA-87, but it would have had no effect on changes in assessment or care planning that we observed and consider precursors to the observed changes in outcomes.

The facilities in our sample were subject to new nurse staffing requirements. These facilities were somewhat better staffed than the average facility in 1990, and a comparison of the 1990 and 1993 OSCAR data indicates that there was no significant change in licensed nurse staffing or aide staffing in the study facilities.

Finally, the changes in the survey process related to quality of care were intimately linked with the intervention itself. The MDS sections and the 18 Resident Assessment Protocols (RAPs) were keyed to the 18 quality of care requirements in the new survey process. If the changes in the survey process, which one must remember is a single visit each year to a facility, improved care, they did so on the foundation created by the RAI.

Although we feel relatively comfortable attributing the observed changes to the implementation of the RAI, it is not immediately clear why the RAI should have reduced the rate at which some residents improved. Our data limit our ability to provide well-substantiated explanations for this unexpected result, but the finding is too important to be left unexplored. A number of potential explanations for these results were considered. However, when tested against the available data, only one explanation maintained credibility. The explanation most consistent with the evaluation data is that the RAI's implementation resulted in the reallocation of care resources from some groups of residents to other groups of residents.

The RAI is problem-focused, emphasizes reducing unnecessary decline, and identifies those residents with multiple problems. At the same time, facilities have implemented the RAI in an environment with relatively stable levels of resources and increasing scrutiny of outcomes by regulators. In the areas of physical functioning, the RAI's emphasis may have interacted with these other factors and caused staff to shift their attention to those residents with the greatest care needs and the highest likelihood of decline. This shift may have come at the expense of those less functionally impaired residents who could have experienced some measure of improvement.

In cognitive performance, understanding, and psychosocial well-being, the pattern of changes is somewhat more complex. One sees less attention to improvement among those least in need (i.e., good ADL and good CPS) and those least likely to benefit (i.e., poor ADL and poor CPS). Efforts at decline reduction in these areas may have been focused on those with the cognitive skills necessary to respond to any cognitive or psychosocial intervention.
This interpretation of our results has important implications for HCFA both in its future revisions of the MDS and in its implementation of the survey process. The implementation of the RAI seems to have effectively focused facilities' attention on specific areas of function and decline for different subpopulations. It is now important that the resources available in the RAI that focus on improvement in both physical function and psychosocial status be brought to bear. This means a greater focus on these issues in revisions in the RAPs, in revisions of the RAI itself, and a greater emphasis on these issues in the survey process.

\section{ACKNOWLEDGMENTS}

The authors gratefully acknowledge the considerable support and assistance provided by the staff in the Health Standards and Quality Bureau.

\section{REFERENCES}

1. Applegate WB, Blass JP, Williams TF. Instruments for functional assessment of older patients. N Engl J Med 1990;322:1207-1214.

2. Reuben DB, Borok GM, Wolde-Tsadik G et al. A randomized trial of comprehensive geriatric assessment in the care of hospitalized patients. N Engl Jed 1995;332:1345-1350.

3. Vetter NJ, Jones DA, Victor CR. Effects of health visitors working with elderly patients in general practice. J R Coll Gen Pract 1979;29:733-742.

4. Reubenstein $L Z$, Josephson $K R$, Wieland GD et al. Effectiveness of a geriatric evaluation unit: a randomized clinical trial. N Engl J Med 1984;311:1664-1670.

5. Hendriksen C, Lund E, Stromgård E. Consequences of assessment and intervention among elderly people: a three year randomised controlled trial. BMJ 1984;289:1522-1524.

6. Williams M. Outpatient geriatric evaluation. Clin Geriatr Med 1987;3:175184.

7. Hogan DB, Fox RA, Badley BWD, Mann OE. Effect of a geriatric consultation service on management of patients in an acute care hospital. Can Med Assoc J 1987;136:713-717.

8. Applegate WB, Miller ST, Graney MJ et al. A randomized, controlled trial of a geriatric assessment unit in a community rehabilitation hospital. $\mathrm{N}$ Engl J Med 1990;322:1572-1578.

9. Hogan DB, Fox RA. A prospective controlled trial of a geriatric consultation team in an acute-care hospital. Age Ageing 1990;19:107-113.

10. Thomas DR, Bryan R, Haywood BP. Inpatient community-based geriatric assessment reduced subsequent mortality. J Am Geriatr Soc 1993;41:344350 .

11. Burns R, Nichols LO. Impact of an outpatient GEM on health status of older veterans. J Am Geriatr Soc 1993;41(Suppl):SA1 (abstract).

12. Allen CM, Becker PM, McVey LJ et al. A randomized, controlled clinical trial of a geriatric consultation team: compliance with recommendations. JAMA 1986;255:2617-2621.

13. Becker PM, McVey LJ, Saltz CC et al. Hospital-acquired complications in a randomized controlled clinical trial of a geriatric consultation team. JAMA 1987;257:2313-2317.

14. Saltz CC, McVey LJ, Becker PM et al. Impact of a geriatric consultation team on discharge placement and repeat hospitalization. Gerontologist 1988;28:344-350.

15. Institute of Medicine. Improving the Quality of Care in Nursing Homes. Washington, DC: National Academy Press, 1986.

16. Hawes $C$. The Institute of Medicine study: Improving quality of care in nursing homes. In: Katz P, Kane RL, Mezey M, Eds. Advances in long-term care. New York: Springer, 1990.

17. Morris JN, Hawes C, Murphy K et al. Resident Assessment Instrument Training Manual and Resource Guide. Natick, MA: Eliot Press, 1991.

18. Phillips $C D$, Hawes $C$, Mor $V$ et al. Evaluating the Effects of the Resident Assessment Instrument: Methodological Issues and Approaches. Research Triangle Park, NC: Research Triangle Institute, 1995.

19. Kane RL, Ouslander JG, Abrass IB. Essentials of Clinical Geriatrics, 2nd Ed. New York: McGraw-Hill, 1989.

20. Morris JN, Mor V, Fries BE et al. A Six-Category MDS-Based ADL Scale. Boston, MA: Hebrew Rehabilitation Center for the Aged, 1993.

21. Hawes C, Morris JN, Phillips CD et al. Reliability estimates for the Minimum Data Set for Nursing Home Resident Assessment and Care Screening. Gerontologist 1995;35:172-178. 
22. Morris JN, Fries BE, Mehr DR et al. MDS Cognitive Performance Scale. J Gerontol Med Sci 1994;49:M174-182.

23. Hartmaicr SL, Sloane PD, Guess HA et al. Validation of the Minimum Data Set Cognitive Performance Scale: Agreement with the Mini-mental State Examination. J Gerontol Med Sci 1995;50A:M128-133.

24. Folstein MF, Folstein S, McHugh PR. Mini-mental state: A practical method for grading the cognitive state of patients for the clinician. J Psychiatr Res $1975 ; 12: 189-198$.

25. Albert $M$, Cohen $C$. The test for severe impairment: an instrument for the assessment of patients with severe cognitive dysfunction. J Am Geriatr Soc 1992;40:449-453.

26. Mor V, Branco $\mathrm{K}$, Fleishman J et al. The structure of social engagement among nursing home residents. J Gerontol Psychol Sci 1995;50B:P1-P8.

27. Phillips CD, Morris JN, Mor V et al. The MDS-SAMS: A sad or anxious mood scale based on the Minimum Data Set for nursing home resident screening (MDS). Paper presented at the Annual Meeting of the Gerontological Socicty of America, 1992.

28. Morris JN, Mor V, Frics BE et al. An MDS-Based Scale Measuring Unscttled Behavior. Boston, MA: Hebrew Rehabilitation Center for the Aged, 1994.
29. Fries BE, Schneider DP, Foley, WJ et al, Refining a case-mix measure for nursing homes: Resource Utilization Groups (RUG-III). Med Care 1994;32:668-685.

30. Shah BV, Barnwell BG, Hunt PN et al. SUDAAN User's Manual, Release 6.0. Research Triangle Park, NC: Research Triangle Institute, 1992.

31. Lair T, Lefkowitz D. Mental health and functional status of residents in nursing and personal care homes. DHHS Publication No. PHS 90-3470. Na tional Medical Expenditures Survey Research Findings 7. Rockville, MD: Public Health Service, Agency for Health Care Policy and Research, 1990.

32. Kane RA, Kane RL. I.ong-Term Care: Principles, Programs, and Policies. New York: Springer, 1987.

33. Hawes $C$, Phillips CD, Mor V et al. The nursing home Resident Assessment Instrument and its effects on process quality. Paper presented at the Annual Meeting of the Cerontological Society of America, 1994

34. Phillips CD, Mor V, Hawes C et al. Development of the Resident Assessment System and Data Base for Nursing Home Residents: Implementation Report. Research Triangle Park, NC: Research Triangle Institute, 1994.

3.5. Rovner BW, Edelman BA, Cox MP, Shmuely Y. The impact of antipsychotic drug regulations on psychotropic prescribing practices in nursing homes. Am J Psychiatry 1992;149:1390-1392. 